\title{
Adaptation Interventions to Promote Participation in Natural Settings
}

\author{
Philippa H. Campbell, PhD; Suzanne Milbourne, PhD; \\ M. Jeanne Wilcox, PhD
}

\begin{abstract}
Children's participation in everyday activities and routines in home and community settings is an important focus of services for infants and young children with disabilities. Data indicate that assistive technology (AT) is not widely used nor do early intervention service providers report frequent use of AT devices with infant-toddlers. Adaptation interventions combine environmental accommodations and AT in ways that promote children's participation in activities and routines and provide functional skill-building learning opportunities. A decision-making process for planning and implementing adaptation interventions is outlined with examples of strategies and formats that service providers can use to create successful interventions for infants and young children. Key words: activities and routines, adaptation, assistive technology, intervention, participation
\end{abstract}

$\mathbf{T}$ HE use of assistive technology (AT) services and devices with infants and toddlers in early intervention (EI) programs appeared to be increasing from 1992 to 1996 (Technical Assistance Project, 2000); however, more recent reports indicate a stable pattern of underutilization (Campbell \& Wilcox, 2004; Dugan, Campbell, \& Wilcox, 2006). National reports of the percentage of infanttoddlers with AT listed as a service/device on their Individual Family Service Plans (IFSPs) have averaged about $4 \%$ in each year since 1999 (U.S. Department of Education, 2006). Furthermore, an analysis of the 2820 service records for infants and toddlers participating in the National Early Intervention Longitudinal Study (Hebbeler \& Zercher, 2003) revealed that AT was listed on $4 \%$ of these service records.

\footnotetext{
Autbor Affiliations: Thomas Jefferson University, Philadelphia, Pennsylvania (Drs Campbell and Milbourne); and Department of Speech and Hearing Science, Arizona State University, Tempe (Dr Wilcox).
}

Corresponding Autbor: Pbilippa H. Campbell, PbD, Thomas Jefferson University, 130 South 9th St, Suite 526, Philadelphia, PA 19107 (philippa.campbell@ jefferson.edu).
A number of explanations for low rates of utilization have been suggested including parent unwillingness to accept device use with their children, provider biases to work on typical skill development, inability to finance devices, lack of consensus about what comprises AT, and limited emphasis on or training about AT in state EI programs (Kemp \& Parette, 2000; Lahm \& Sizemore, 2002; Sullivan \& Lewis, 2000). Furthermore, it has been suggested that state policies such as uniform Individual Family Service Plans (IFSPs) that do not require documentation of AT devices may under-represent actual AT utilization by not providing mechanisms for reporting actual use (Lesar, 1998). In a national survey of 967 EI providers, $44 \%$ reported that either none or few of the children they served who needed AT were in fact receiving AT services or devices (Wilcox, Guimond, Campbell, \& Weintraub-Moore, 2006).

The Tots-n-Tech (T-n-T) Research Institute on Assistive Technology for Infants and Toddlers has conducted a number of studies to explore utilization of AT with infants (Campbell \& Wilcox, 2004). In an analysis of data from 2 national surveys, more than $90 \%$ of 424 EI providers reported positive 
perspectives about providing AT for infants and toddlers (Dugan et al., 2006). These same providers were interviewed to explore decision making about what types of interventions would be considered in which developmental situations and at what time points within the infant-toddler age range. The questions focused on decisions about mobility, communication, self-care, and play situations. Each question was structured so that respondents selected an option from a series that was representative of several intervention categories (eg, low tech, high tech, skill building, not a concern at this time). These options were repeated within each of 3 agelevel categories of less than 12 months, 12 to 24 months, and more than 24 months. To contrast the perspectives of EI service providers with those of providers serving children with the most severe disabilities, 37 coordinators of State Deaf-Blind Programs completed a written questionnaire using the same series of questions. For the most part, Deaf Blind coordinators reported use of both lowor high-technology interventions at younger ages than did the EI providers. Although EI providers reported beliefs that supported early use of AT, they did not report actual use until children were over 2 years old. As a whole, a majority of EI providers selected skill-building interventions as a primary intervention across all functional areas for children younger than 2 years and almost a third of the providers continued to select skill-building options even when children were older than 2 years.

\section{ACCOMMODATION, ADAPTATION, UNIVERSAL DESIGN, AND AT}

To gain an understanding of perspectives about definitions of AT, T-n-T surveyed 967 EI providers and asked them to provide examples of devices they considered to be low and high technology (Wilcox, Dugan, Campbell, \& Guimond, 2006). Providers were more likely to mention low- than hightechnology devices. However, the same devices (eg, communication devices) were fre- quently mentioned as examples in both the low-technology and high-technology category. These data as well as other reports (eg, Lahm \& Sizemore, 2002; Parette \& Brotherson, 2004) seem to indicate that service providers may not have a clear definition of either what AT services and devices include or when to use them with children.

Part of the apparent confusion for providers may relate to the different terminology and definitions about AT that are incorporated into federal programs that support individuals with disabilities. For example, each state includes definitions of Durable Medical Equipment (DME) that are eligible for payment under state Medicaid programs. Our T-n-T data suggested that providers seemed to link their own state definitions of DME, a source of funding for AT, with their personal definitions of high-technology AT. The Americans with Disabilities Act (1990) protects rights of individuals with disabilities in a variety of situations and settings including child care programs. Legislation specifies that discrimination cannot take place without reasonable accommodation for an individual's disability. Reasonable accommodations include changing facilities so that they are accessible (eg, installing a ramp into a child care program for a child in a wheelchair) and acquiring or modifying materials (eg, providing adapted positioning equipment for a child with physical disabilities or special materials for a child who is blind or visually impaired).

Regulations for both the Assistive Technology Act of 1998 (as amended, 2004) and the Individuals with Disabilities Education Improvement Act (2004) include identical definitions for both AT services and AT devices. The definition of devices is expansive and includes any item, equipment, or product system that is used to "increase, maintain, or improve functional capabilities of an individual with a disability" (CFR 300.5). These definitions are broad, linked specifically to functional capabilities, and incorporate some, but not all, items that would be likely to be included under Medicaid DME categories 
or under the reasonable accommodation requirement of the Americans with Disabilities Act (ADA).

AT is beginning to be viewed within a context of universal design, a new concept being incorporated into federal programs. The proposed regulations for IDEA [Federal Register: June 21, 2005 (Vol 70, No. 118)] reference this concept by adding the same definition for this term that is included in the Assistive Technology Act. Universal design means "a concept or philosophy for designing and delivering products and services that are usable by people with the widest possible range of functional capabilities, which include products and services that are directly accessible (without requiring assistive technologies) and products and services that are inter-operable with assistive technologies" (CFR 300.43). When devices and other materials are designed in such a way as to be useable by people with disabilities, the modifications, adaptations, or special devices that are defined as AT are not needed. For example, universal design includes many modifications that may have originally been designed for individuals with disabilities but are useable by children and adults without disabilities such as curb cuts, high toilets, positioning devices for infants such as stroller or car seat head protectors, cardboardpaged books, or built-up handled spoons. Under IDEA, the concept of universal design is strongly linked to assessment and curriculum and is viewed as a way to provide children with access to the general education curriculum. When child care or preschool curricula, for example, are designed for children with a range of abilities, then fewer modifications, adaptations, or AT devices are needed for a child with a disability to participate successfully in a program's curricular activities. For example, when playgrounds are designed to accommodate all children's abilities, then the modification and adaptations necessary to provide access and promote participation of children with disabilities are minimized or eliminated. Or, when items such as knob crayons are used in programs for all young children, a child with difficulty grasping is more likely to be able to participate in a coloring activity.

The often-subtle differences in definitions and terms for accommodation, AT, or universal design may make little difference to families who want their children to be able to participate in typical activities and routines or to child care providers or preschool teachers who also have expectations for children's participation (Milbourne \& Campbell, 2007). We have taken an approach in our work of combining the reasonable accommodation definitions from the ADA and the AT definitions used in IDEA and the Assistive Technology Act to propose a category of intervention that we have labeled "adaptation" and which both encompasses features labeled as accommodation or AT devices and acknowledges concepts of universal design.

\section{TYPES OF INTERVENTIONS}

Adaptation interventions are a type of intervention where therapists and teachers assist in the identification, design, fabrication, and monitoring of interventions that are provided by families and other caregivers within the context of typical activities and routines. These interventions function as a "bridge" or a mediator between the skills that a child can currently perform and the requirements or expectations of the activity. When there is a mismatch between a child's current abilities and the requirements of an activity, adaptation interventions may allow a child to participate fully even without being able to perform the required skills (Campbell, 2004). All children may be able to participate more easily or successfully in various activities when adaptations are used. For example, a typical infant rides more easily and safely in a car when positioned in a car seat. However, when a preschooler is unable to sit because of a physical disability, a car seat may be essential to successfully ride in a car.

Use of typical activities and routines that occur in natural settings as a context for intervention has been emphasized in EI (Dunst et al., 2001; Dunst, Hamby, Trivette, \& Bruder, 
2000). Adaptation interventions, including accommodation and AT, are used to help children participate in typical activities and routines within the everyday settings where they spend time (Campbell, 2004; Lane \& Mistrett, 2002; Milbourne \& Campbell, 2007; Mistrett, 2004). AT can be used with children with a wide range of developmental concerns ranging from mild delays in development to children with severe or multiple disabilities. Its use may both promote participation and help children with functional skill limitations achieve mobility, communication, play, or self-care skills (Blackhurst \& Lahm, 2003; Mistrett, 2001). Specialized teaching or therapy strategies are another type of intervention used to teach children to perform these same skills naturally or without extensive use of adaptations or devices (Campbell, 2005). These skill-building interventions are traditionally provided via one-on-one interactions between children and EI personnel and take place during home visits (Campbell \& Sawyer, 2007). In preschool and child care, children may receive one-on-one interactions with therapists or teachers via a "pullout" model. Services provided through one-on-one interaction between a child and an adult are generally described as a direct intervention because of their dependence on contrived activities and intense adult intervention.

When promoting participation, the focus of intervention shifts from skill building to include strategies that ensure maximal participation as quickly as possible. Adaptation interventions include use of both low- and high-technology AT devices that allow children to participate in the absence of being able to perform skills required in the activity or routine. For example, a child may be unable to participate in art activities at the child care center because she is unable to grasp objects such as art materials, brushes, or crayons without adult assistance. The requirement of an adult to help the child hold and manipulate objects may alter the child's participation by isolating the child from other children, thereby limiting natural opportunities for peer interaction, communication, or other group expectations. Providing the child with adapted brushes, crayons, or other materials and having the child care program choose art activities that do not require high levels of manipulation of objects may allow the child to participate without adult assistance, thereby providing natural opportunities for communication and social interaction.

\section{DECISION MAKING USING AN ADAPTATION HIERARCHY FRAMEWORK}

A 4-step process for making decisions about possible adaptations to promote children's participation in activities and routines is illustrated in Figure 1. It may be helpful to reframe skill-building goals (eg, "use a pincher grasp"; "write 4 capital letters when provided with a model"; "express wants and needs when asked") as participation-based outcome statements such as "participate in family mealtimes by feeding himself finger and spoon foods, drinking from a cup, and socializing with family members." Participation-based outcomes establish the child's goal as one of participation in a specified activity (or routine) rather than as skill building although an activity or a routine provides a context in which to practice particular skills. For example, mealtimes that specifically include finger foods may provide a child with opportunities to practice using a pincher grasp.

\section{GATHERING INFORMATION}

As an initial step in designing adaptation interventions, providers first work with families or other child caregivers (eg, child care providers; preschool teachers) to learn about the typical activities and routines in which the child participates or is unable to participate. Family activities include a wide range of situations, some of which are typical across families (eg, grocery shopping; watching TV), but many of which may be unique and based on family preferences (eg, playing at the beach). Child care and other group activities (eg, library story book hour; toddler music or gymnasium programs) also include 
Step 1: Gather information about family activities

- identify 1 or more activities in which the family/child participate out side of the home (eg, playground, shopping);

- identify activities that occur within group situations such as child care or community activities (eg, swimming lessons);

- identify family activities-routines (eg, mealtimes, playing)

- find out which activities-routines go well for the family and which they are not satisfied with and/or do not go well; and

- find out which activities-routines go well or do not go well in situations such as child care or community activities (from parent, child care provider, etc)

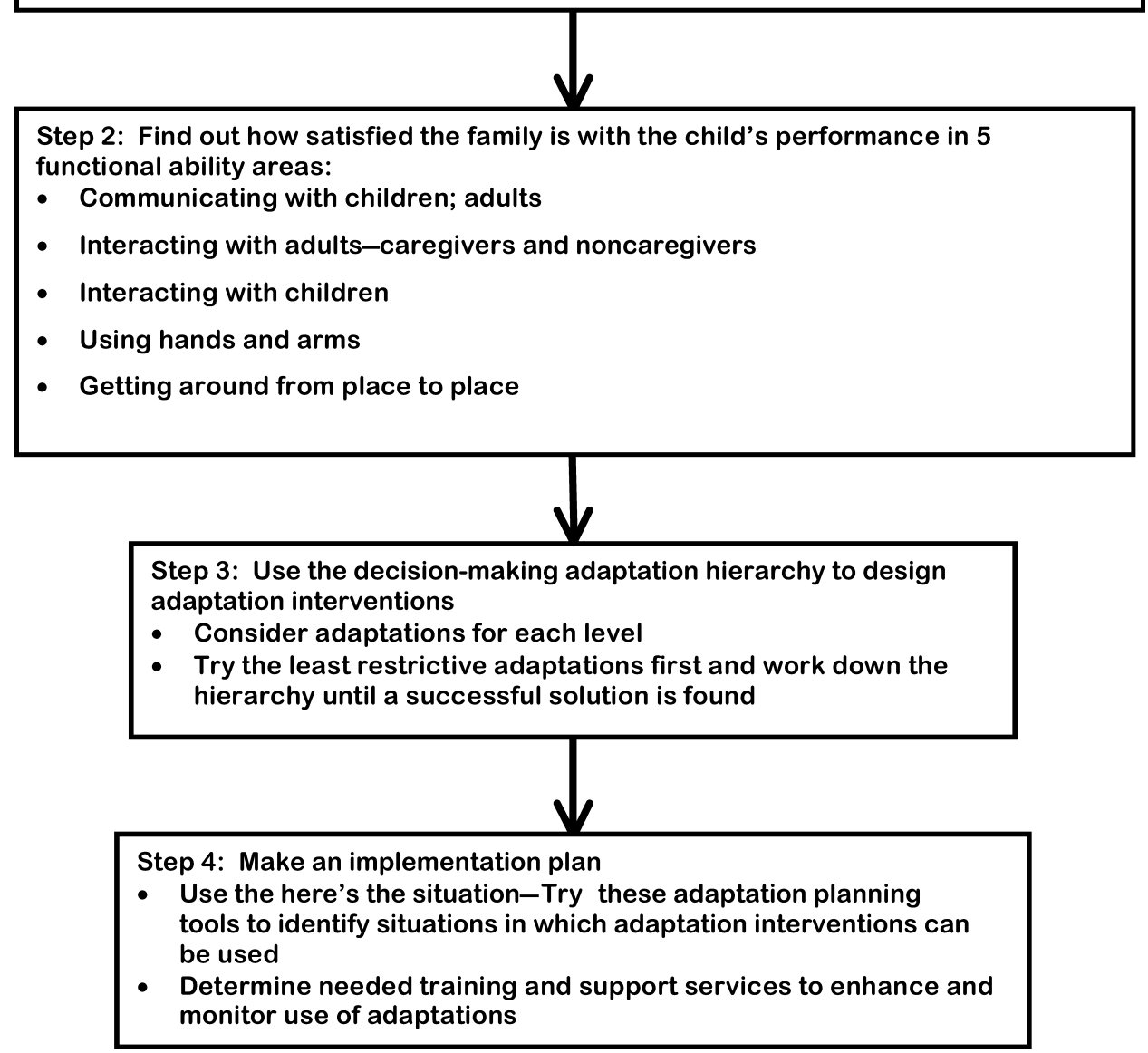

Figure 1. A 4-step process for making adaptation decisions to promote children's participation in activities and routines.

participation opportunities such as storybook reading, learning centers, gross motor activities, or snack. Family routines occur regularly and often involve caregiving (eg, bathtime) or family organization (eg, getting up in the morning; bedtime; mealtimes). In child care, most routines are those that involve caregiving (eg, diaper changing, toileting, naptime) or provide structure for managing groups of children (eg, making a transition from one activity to another; leaving at the end of the program). Service providers can learn about activities and routines in a variety of ways ranging from simply having a conversation with the family or caregiver-teacher to using more structured assessment techniques. 


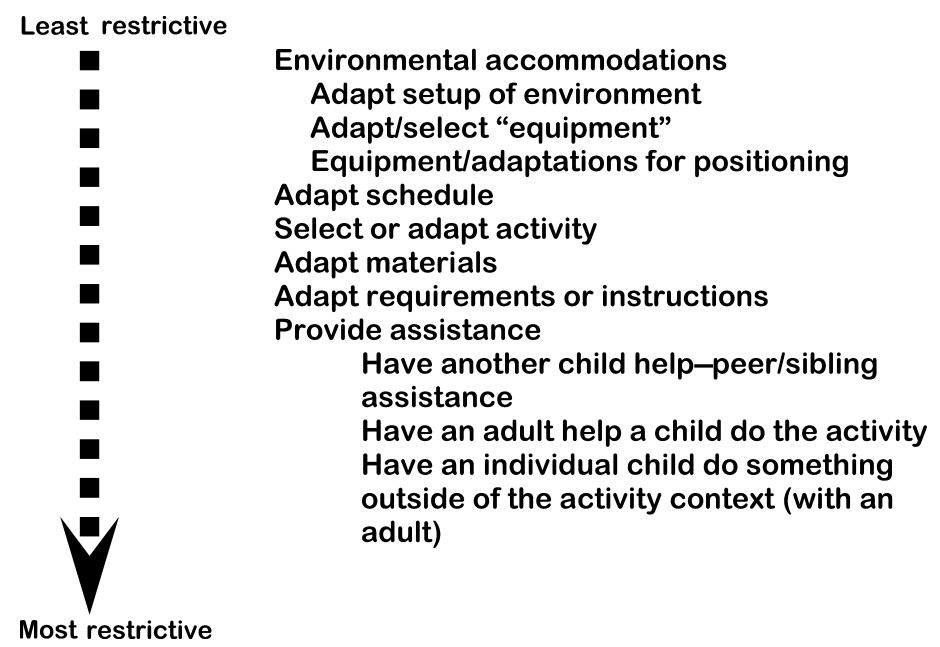

Figure 2. A hierarchy for designing adaptation interventions including assistive technology devices and ranging from environmental accommodations (least restrictive) to adult assistance (most restrictive).

The important thing is to find out about the activities and routines that are not going well as judged from the perspective of the family or caregiver-teacher. The end goal of the process is to promote children's participation in all identified activities and routines but particularly in those that are judged by families or others (eg, child care staff; librarian) as not going well (Campbell, 2004, 2005).

The second step is to learn about adults' satisfaction with the child's performance in 4 functional skill areas including communication, social interaction with adults and children, use of hands and arms, and mobility. Children with disabilities may have many developmental performance limitations but these limitations may or may not impact negatively on participation in specified activities and routines. When functional skill abilities negatively influence participation in a particular activity or routine, these limitations may often be reduced or eliminated through use of adaptations. For example, if a child needs to ask for more food or drink during snack time at a child care center, holding the 2 objects up so that the child can indicate a choice, a picture board that allows a child to point to items, a picture exchange system, or using a simple voice output device can allow the child to par- ticipate in snack time and meet adult expectations without being able to talk.

\section{ADAPTATION HIERARCHY FRAMEWORK}

The third step is to use the adaptation hierarchy framework (Fig 2) for making decisions about possible adaptation strategies to help a child successfully participate in typical activities and routines (Campbell, 2004, 2005; Milbourne \& Campbell, 2007). The hierarchy lists categories of intervention strategies from those that are least (at the top) to most (at the bottom) restrictive. Modifying the environment in some way that allows a child to participate or providing a child with specific types of equipment is the least intrusive type of adaptation strategies. Removing a child from the typical environment so that the child is doing something different with an adult, generally in a one-on-one situation, is the most restrictive. The framework is not meant to suggest that more restrictive options are never needed in particular situations or with certain children but rather that restrictive interventions should not be tried as a first solution and should be used only when other categories of adaptation have been tried with no success. 
Assistive technology devices, as defined in IDEA and other legislation, fit into the adaptation hierarchy primarily within categories of environmental adaptations of positioning and selection or adaptation of materials. Other non-AT types of adaptation may be used to promote child participation. Intervention strategy categories that are at the top of the chart typically involve accommodations or adaptations to the environment in which an activity or a routine occurs. For example, arranging the furniture at home or in a child care program so that the child can get around is an example of an environmental accommodation. Placing heavy sandbags into plastic furniture (eg, a play kitchen) so that a child can use the furniture safely to pull up to standing is an example of an environmental modification. Purchasing puzzles with big knobs on the pieces or adapting existing puzzles with big knobs allows a child without good manipulation skills to play with other children. When adaptations do not occur, children must be assisted by other children or by adults to participate successfully. Requiring assistance from an adult to participate in an activity or a routine is a restrictive intervention.

Examples of strategies for each of the adaptation intervention categories on the hierarchy are listed on Table 1. Further examples can be found in Milbourne and Campbell (2007). Typically developing infants and toddlers share many of the same functional skill limitations as children with disabilities and these limitations are likely to impact their participation in activities and routines. As a result, equipment, toys, and other items used with typically developing children can be used with children with disabilities if carefully selected and matched to the child's interests and abilities. In a sense, items used with babies have universal design characteristics and may require little to no adaptation to promote participation with children with disabilities. These items include baby equipment such as highchairs, strollers, toilet chairs, floor sitters, or child chairs that are readily available but need to be carefully selected to provide the types of support that may be needed by a child with a disability. Purchasing carefully selected toys that match a child's interests and manipulation abilities or can be easily adapted to accommodate for any functional ability limitation also is effective for a majority of infants and young children. Inexpensive adaptations to off-the-shelf items also work well. For example, a preschooler who can physically fit into a motorized off-the-shelf car (eg, Corvette; Barbie jeep) may be able to use the car for outside mobility with simple adaptations for positioning and switch operation of the car.

Similarly, many of the activities and routines in which infants and young children participate can be easily adapted to allow children with disabilities to participate without any greater amount of adult assistance than would be provided for a child of the same chronological age. Items used within an activity such as specific materials (eg, materials in the kitchen area of a child care room; books) or toys often require no adaptation if well selected or minimal adaptation to accommodate a child's functional abilities. A preschooler with disabilities may be able to learn to "write" the letters in his name by moving magnetic letters around on a board or play at the woodworking area if tools are adapted with built-up handles. In families, and children's programs where children of a variety of ages are included, older or more competent children may be able to help children with disabilities. Early learning program curricula that use multiage groupings (eg, Montessori or Reggio-Emila) offer many opportunities for bringing children together in cooperative working relationships so that children with disabilities have natural forms of assistance.

All of these adaptation strategies can allow a child with a disability to be successful without requiring above-average adult assistance. Obviously, young children require considerable assistance from adults when they are infant or toddler-aged and the amounts and types of assistance decrease as children get older. Children with disabilities are viewed frequently as needing a lot of adult assistance to participate in settings that are designed for typical children. A goal in using adaptation interventions 
Table 1. Examples of adaptation interventions

\begin{tabular}{|c|c|}
\hline Adaptation hierarchy level & Examples \\
\hline Adapt setup of environment & $\begin{array}{l}\text { Moving furniture within the home to allow a child to walk with a } \\
\text { walker; placing all unsafe materials (such as cleaning solutions) } \\
\text { in a locked cupboard }\end{array}$ \\
\hline Adapt/select "equipment" & $\begin{array}{l}\text { Using boppies and bean bag chairs in a child care program so that } \\
\text { children can sit with support; purchasing a particular brand } \\
\text { off-the-shelf stroller or off-the-shelf toilet chair in which a child } \\
\text { can sit comfortably and safely }\end{array}$ \\
\hline $\begin{array}{l}\text { Equipment/adaptations for } \\
\text { positioning }\end{array}$ & $\begin{array}{l}\text { Using a stander so that the child can work with others at the sand } \\
\text { table; obtaining a customized chair that positions the child }\end{array}$ \\
\hline Adapt schedule & $\begin{array}{l}\text { Allow longer times for mealtime so that a child who needs more } \\
\text { time to self-feed will have enough time to complete the meal; } \\
\text { plan an art activity in which children complete } 2 \text { projects to } \\
\text { provide enough time for a child with a disability to complete } \\
\text { one project }\end{array}$ \\
\hline Select or adapt activity & $\begin{array}{l}\text { Reading a story using props so that children may participate } \\
\text { actively while listening; incorporating a variety of riding toys } \\
\text { into outside play so that all children can ride; making sure that } \\
\text { one riding toy can be used by the child with a disability either } \\
\text { through selection or adapting existing toys; singing songs during } \\
\text { opening circle/morning meeting time so that all children have } \\
\text { an opportunity to vocalize }\end{array}$ \\
\hline Adapt/select materials \& toys & $\begin{array}{l}\text { Purchasing an off-the-shelf puzzle with knobs so that the child can } \\
\text { complete the puzzle independently; attaching a switch to a toy } \\
\text { so that the child can play with the toy without assistance }\end{array}$ \\
\hline $\begin{array}{l}\text { Adapt requirements or } \\
\text { instructions }\end{array}$ & $\begin{array}{l}\text { Allowing a child to self-feed for the beginning of the meal and then } \\
\text { feeding the child for the remainder; use picture boards that } \\
\text { relate to a story so that a child can successfully "talk" about the } \\
\text { story or answer story questions.; read } 2 \text { very short stories and } \\
\text { require a child who has difficulty attending to attend for one } \\
\text { story only; construct or select situations for children to request } \\
\text { assistance; allow the use of picture boards, voice output devices, } \\
\text { or other means (eg, sign, gestures) for children who are unable } \\
\text { to speak }\end{array}$ \\
\hline
\end{tabular}

IS for children is to be as independent as other children of the same chronological ages.

\section{IMPLEMENTING ADAPTATION INTERVENTIONS}

The fourth step is to make decisions about how potential adaptation interventions will be implemented. Implementation may be as simple as selecting or designing an adaptation that both "fits" a child's abilities and the characteristics of the activities and routines in which the adaptation promotes participation and, then, providing the adaptation. However, more often than not, family members and caregivers who will use the adaptation intervention with the child will need some explanation and may require actual training. When more complex AT devices have been selected, training and monitoring are built into the implementation plan to ensure that the adults can support the child in using the device and that device operation is monitored to ensure that the device is working as expected. 
Using adaptations \& assistive technology to promote children's participation \& learning here is the situation --- try this adaptation!!

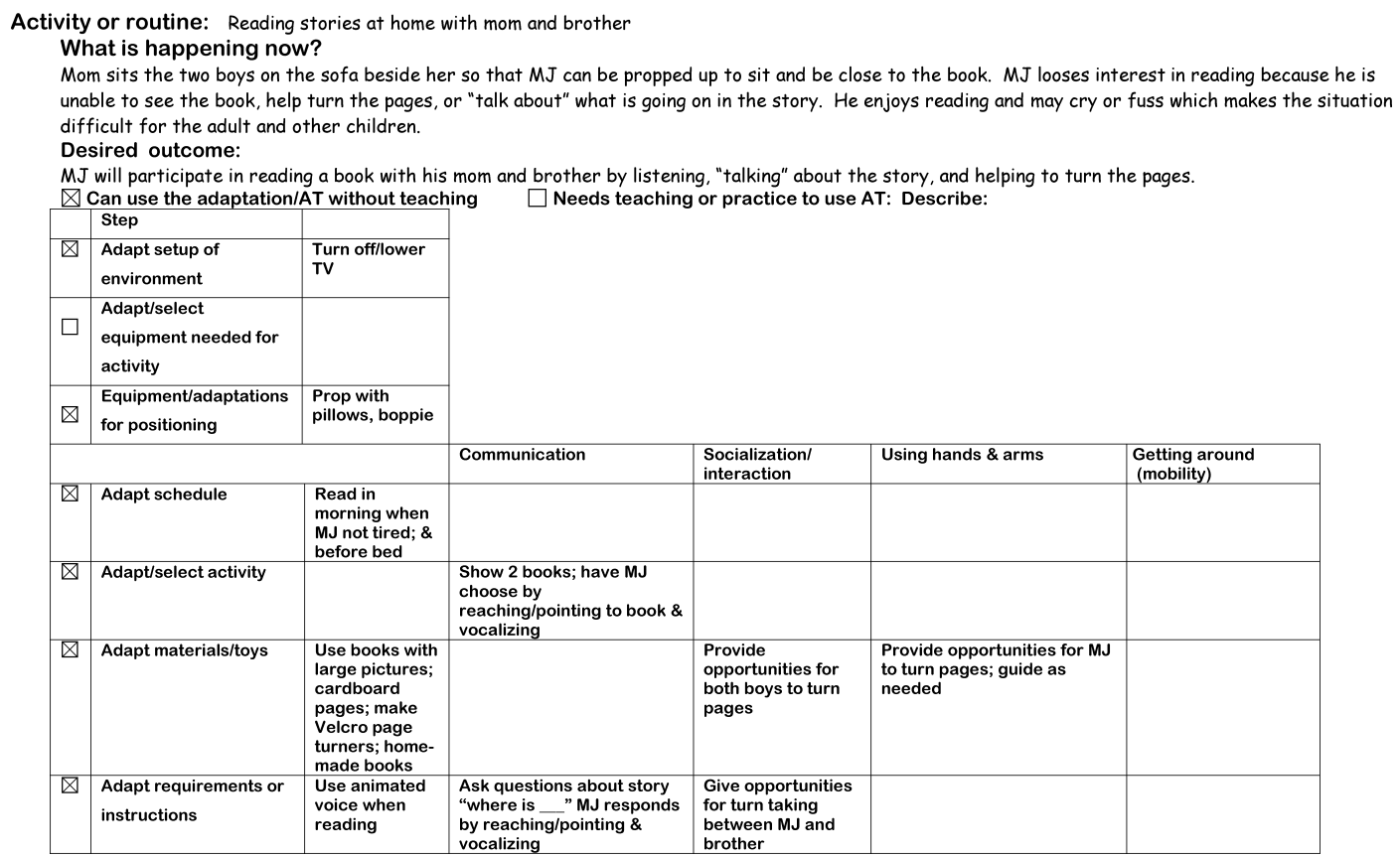

Figure 3. The "Here's the Situation: Try This Adaptation" form was completed for a 20-month-old whose family used storybook reading as part of their bedtime routine.

Abandonment of AT devices (ie, rejecting their use) has been reported as a frequent occurrence when parents, other caregivers, or teachers cannot adequately support the child's device use or maintain its use within desired activities and routines (eg, Mistrett, 2001; Parette \& McMahon, 2002).

One example of an implementation tool is the "Here's the Situation: Try This Adaptation" (Fig 3) matrix that may be used to summarize and represent information that has been gathered about a child's participation in a specified activity or routine. Planning forms provide structure for brainstorming and identifying potential adaptation interventions. Figure 3 illustrates this process using the matrix. Functional skills are listed and matched with steps of the adaptation hierarchy. This particular format has been used to guide professionals and families in identifying potential adaptation strategies and structuring decision making about which strategies to try. The child whose plan is represented on Figure 3 is a 20-month-old who enjoys books. In his family, book reading is part of the children's bedtime routine in which this activity provides a transition between bathing and bedtime as well as an activity for other times during the day. Implementation forms such as this are completed through discussion with the family by an interventionist or EI team. They serve a function of focusing on promoting participation in a specified activity or routine and structuring opportunities for communication, mobility, hand and arm use, and socialization.

The second tool (Fig 4) is a web that can be used in 2 ways. One way is to represent how a particular activity provides opportunities for a child to practice various functional skills. With the use of successful adaptations, children are not only able to participate in the activity but also provided natural opportunities for learning and practicing skills. Skills may be those that are developmentally 


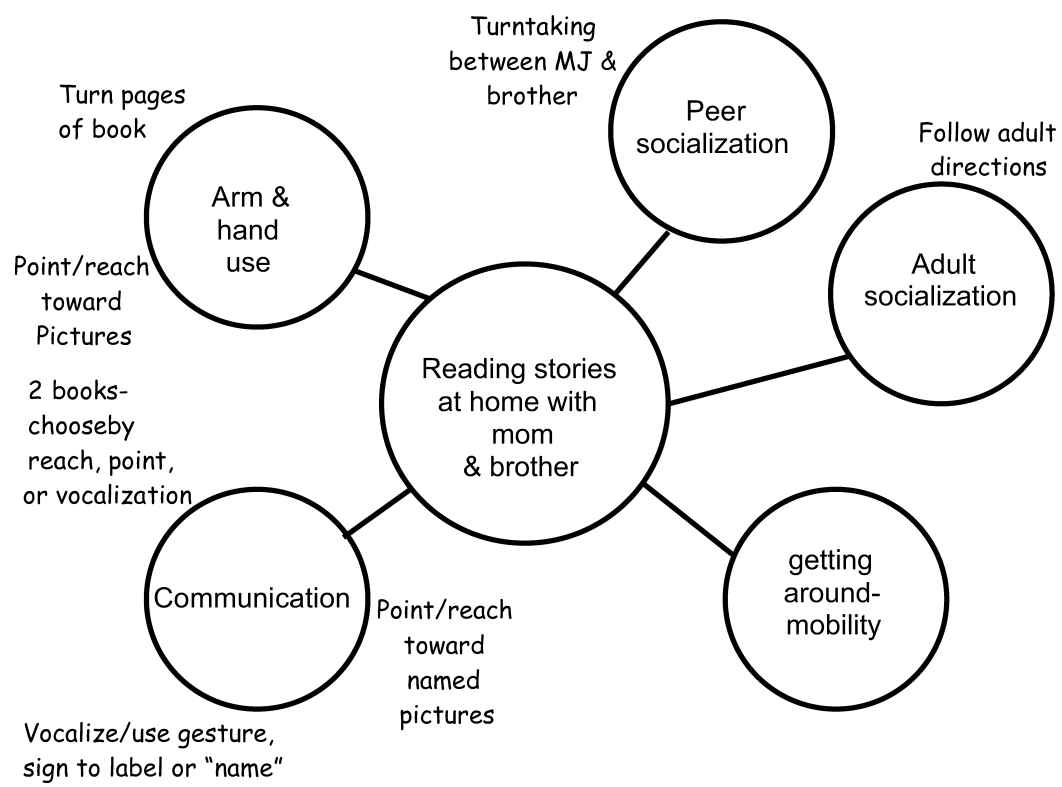

Figure 4. Webs can be used to represent a child's skill learning opportunities within a particular activity or routine as is illustrated in this web of a bedtime routine of storybook reading.

appropriate for all children of a particular chronological age or have been identified for learning on the child's IFSP or IEP. Figure 4 illustrates the web for the same child whose "Here's the Situation" plan is illustrated on Figure 3. Webs provide a context for integrating the perspectives and expertise of various disciplines and help families understand how family activities and routines are important to children's learning of developmental skills such as communication, social interaction, mobility, and arm and hand use. Representing opportunities for learning within the context of a particular family activity or routine may help families understand how they are effective teachers for their children.

It is not unusual for children's abilities in a particular functional skill area to limit participation in more than 1 activity or routine. For example, when children have difficulty communicating, their inability in this area is likely to impact successful participation in more than 1 activity or routine. A second way that webs may be used is to represent the ways in which a particular adaptation intervention can be used across activities and routines. The web in Figure 5 illustrates how adaptations for communication can be integrated into various activities and routines. This web was designed for a 40-month-old girl who attends a child care center while her mother is at work. Molly is the only child with a disability in her child care classroom and her difficulties with communication influenced her abilities to participate successfully in most child care activities. When she was unable to communicate successfully, she often became frustrated and resorted to inappropriate behavior (such as crying, throwing objects, hitting) to gain the attention of the other children or teachers. A series of communication options was designed to be used across the activities in her child care program and represented for the teacher and family on a web so that the use of these strategies was illustrated across activities.

\section{PUTTING IDEAS INTO PRACTICE}

The potential of adaptation interventions is substantial. However, service providers 


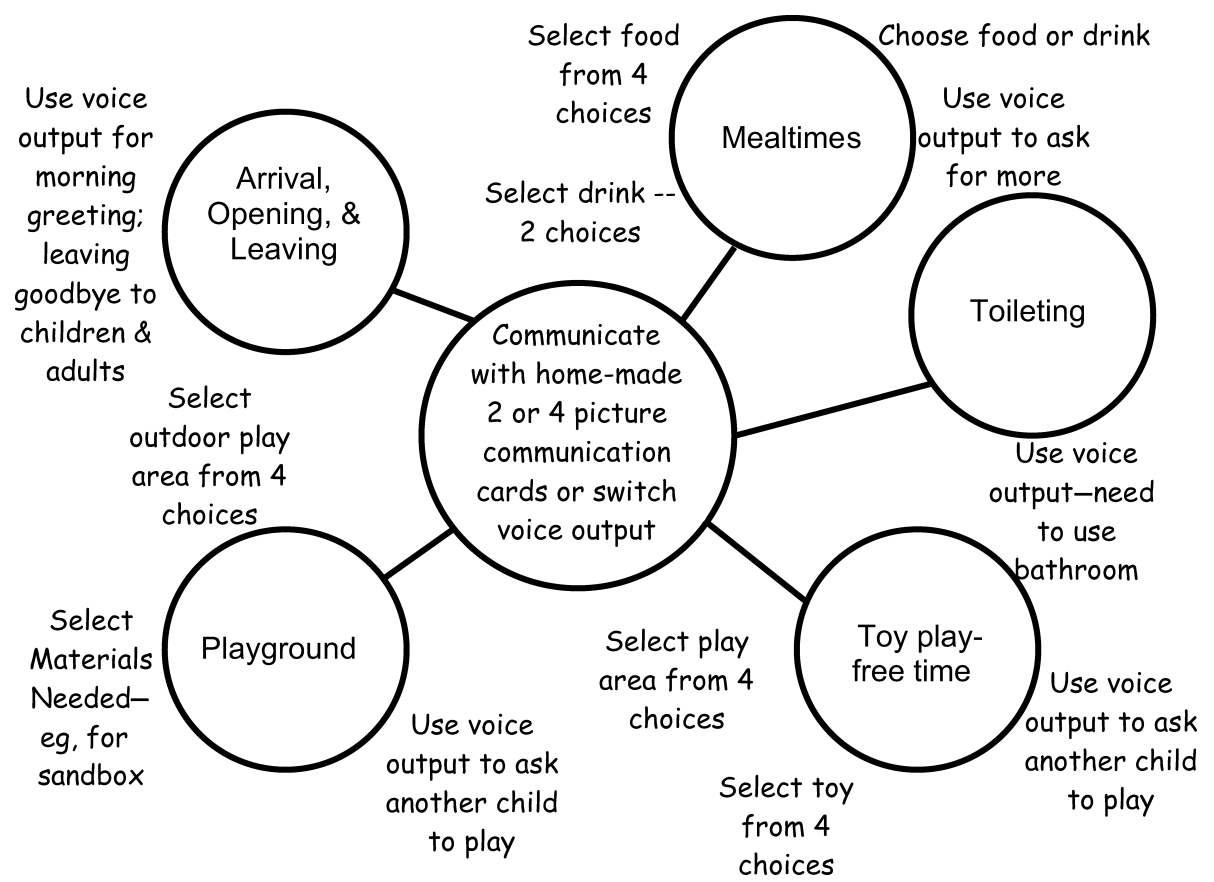

Figure 5. Children's functional skill abilities may negatively influence participation in more than 1 activity or routine. Webs can be used to represent the ways in which particular adaptation interventions may be incorporated into more than 1 activity or routine.

may not readily use adaptation interventions because they are more focused on traditional skill building than on children's participation in activities and routines (Bruder, 2000; Dugan et al., 2006), are unaware of decisionmaking strategies or of potentially helpful resources (Romski \& Sevcik, 2005), or lack knowledge and training about adaptations (Long, Huang, Woodbridge, Woolverton, \& Minkel, 2003). All providers should be aware of AT resources provided through their Part $C$ lead agency, special education in their state Departments of Education, or the agency that administers the state's Assistive Technology Act grant. By using these resources, many states have been able to offer training about AT services and devices, devices within a particular skill category (eg, Augmentative and Alternative Communication), or on specific device products. Some states provide annual Expos where devices can be seen and tried and manufacturers or distributors can answer questions. These opportunities are generally directed to AT applications with individuals of all ages and may not be specific to AT with infants and young children.

Trying out devices is often helpful, particularly with high-technology or specialized devices that may be both costly and complicated. Sometimes a device that seems plausible may not work well in given situations. Lending libraries are a helpful and effective resource for learning about devices and obtaining them for trial before purchase. Some states have established lending libraries within community facilities such as public libraries and others provide these programs on a regional or statewide basis. Lending libraries are also operated by private organizations such as Easter Seal or United Cerebral Palsy Associations and by Lekotek. Most lending libraries have both low- and high-technology items available to borrow but, in general, available items are more likely to be considered as high-technology. Providers should explore public and private 
resources in their own states and familiarize themselves with what items are available to borrow, any eligibility requirements, and procedures for obtaining and trying devices.

With infants and young children, hightechnology devices are seldom needed. A preschooler with a disability may be able to participate at the classroom computer learning station by accessing the computer with a touch screen and this adaptation may be used by the other children in the classroom. When keyboarding skills are needed, a more complicated adaptation may be necessary for effective computer use. Infants or toddlers may be able to augment limited speech and improve communication through use of pictures or a simple voice output device but may require more complicated communication aids to express themselves as they get older. While environmental adaptations and low-technology aids are less costly and permanent than hightechnology devices, information is needed to be knowledgeable about the range of options that are available to both promote participation and improve functional skill use. Early intervention providers and families may require training and resources to identify potential aids that can be used. In addition, often the most effective adaptation interventions are those that are designed through creative problem solving and trial-and-error use. Providers should be willing to experiment to identify ways that children's participation and skill use can be improved.
A reality is that few EI providers receive training about adaptations or devices or about how to provide AT services (Lahm \& Sizemore, 2002; Wilcox et al., 2006). Studies of professional training programs for EI personnel (eg, teachers, therapists) indicate that few programs include information about designing or using adaptation interventions (Stayton \& Bruder, 1999) but emphasize strategies for teaching targeted skills.

Adaptation interventions have the potential to be powerful interventions with infants and young children. However, in telephone interviews with families whose children were using AT devices, a majority of families reported that they learned about adaptations and devices from friends and other families-not from professionals (Wilcox et al., 2006). This finding is probably not too surprising, given the limited training that providers receive and their reliance on intervention decision making that delays the use of adaptation interventions until children are older. Optimally, adaptation interventions would be introduced to providers during their preservice training, supported by state and local policy, and maintained through ongoing inservice training and availability of local resources such as device lending libraries. When providers are knowledgeable about and view adaptation interventions as effective ways of intervening with infants and toddlers, children's performance of functional skills and participation in everyday activities and routines can be enhanced.

\section{REFERENCES}

Americans with Disabilities Act of 1990, P.L. 101-336.

Assistive Technology Act of 1998 as Amended (2004), P.L. 108-364.

Blackhurst, E., \& Lahm, L. (2000). Functional decision making model for assistive technology. In J. Lindsey (Ed.), Computers and exceptional individuals (revised ed., pp. 159-177). Columbus: Merrill.

Bruder, M. B. (2000). Family-centered early intervention: Clarifying our values for the new millennium. Topics in Early Childbood Special Education, 20(2), 105115.

Campbell, P. H. (2004). Participation-based services:
Promoting children's participation in natural settings. Young Exceptional Children, 8(1), 20-29.

Campbell, P. H. (2005). Addressing motor disabilities. In M. E. Snell \& F. Brown (Eds.), Instruction of students with severe disabilities (6th ed., pp. 291-327). New York: Prentice Hall/Merrill.

Campbell, P. H., \& Milbourne, S. A. (2002). Philadelphia inclusion network, instructor guidelines. Available from Thomas Jefferson University, Child and Family Studies Research Programs, 5th Floor Edison, 130 S. 9th St., Philadelphia, PA 19107. Retrieved July 1, 2005, from http://jeffline.jefferson.edu/ cfsrp/products/materials-pin1.html 
Campbell, P. H., \& Sawyer, L. B. (2006). Supporting learning opportunities in natural settings through participation-based services. Journal of Early Intervention, 21(2), 94-106.

Campbell, P. H., \& Wilcox, M. J. (2004). Briefing book: Tots $n$ Tech Research Institute on assistive technology for infants and toddlers. Available from Thomas Jefferson University, Child and Family Studies Research Programs, 5th Floor Edison, 130 S. 9th St., Philadelphia, PA 19107.

Dugan, L., Campbell, P. H., \& Wilcox, M. J. (2006). Decision-making about assistive technology use with infants and toddlers. Topics in Early Childbood Special Education, 26(1), 25-32.

Dunst, C. J., Bruder, M. B., Trivette, C., Hamby, D., Raab, M., \& McLean, M. (2001). Characteristics and consequences of natural learning opportunities. Topics in Early Childbood Special Education, 21(2), 68-92.

Dunst, C. J., Hamby, D., Trivette, C. M., Raab, M., \& Bruder, M. B. (2000). Everyday family and community life and children's naturally occurring learning opportunities. Journal of Early Intervention, 23(3), 151-164.

Hebbeler, K., \& Zercher, C. (2003, October 13). NEILS: Service and provider characteristics and expenditures. Paper presented at the 19th Annual Conference of the Division for Early Childhood (DEC), Washington, DC.

Individuals with Disabilities Education Improvement Act of 2004, Pub. L. 108-446.

Individuals with Disabilities Education Improvement Act of 2004 Proposed Regulations. (2005). Federal Register, $70(118)$.

Kemp, C. E., \& Parette, H. P. (2000). Barriers to minority family involvement in assistive technology decisionmaking processes. Education and Training in Mental Retardation and Developmental Disabilities, 35(4), 384-392.

Lahm, E. A., \& Sizemore, L. (2002). Factors that influence assistive technology decision-making. Journal of Special Education Technology, 17(1), 15-26.

Lane, S., \& Mistrett, S. (2002). Let's play! Assistive technology interventions for play. Young Exceptional Children, 5, 19-27.

Lesar, S. (1998). Use of assistive technology with young children with disabilities: Current status and training needs. Journal of Early Intervention, 21(2), 146159.

Long, T., Huang, L., Woodbridge, M., Woolverton, M., \& Minkel, J. (2003). Integrating assistive technology into an outcome-drive model of service delivery. Infants and Young Children, 16, 272-283.

Milbourne, S., \& Campbell, P. H. (2007). CARA's Kit: Creating adaptations for routines and activities. Philadelphia: Thomas Jefferson University, Child and Family Studies Research Programs. Distributed by DEC (www.dec-sped.org).

Mistrett, S. (2001). Synthesis on the use of assistive technology with infants and toddlers (birth through age two) (Contract No. HS97017002, Task Order No. 14). Washington, DC: U.S. Department of Education, Office of Special Education Programs, Division of Research to Practice.

Mistrett, S. (2004). Assistive technology helps young children with disabilities participate in daily activities. Technology in Action, 1(4), 1-8.

Parette, H. P., \& Brotherson, M. J. (2004). Familycentered and culturally responsive assistive technology decision-making. Infants and Young Children, 17(4), 355-367.

Parette, P., \& McMahan, G. A. (2002). What should we expect of assistive technology?: Being sensitive to family goals. TEACHING Exceptional Cbildren, 35(1), 56-61.

Romski, M., \& Sevcik, R. A. (2005). Augmentative communication and early intervention: Myths and realities. Infants and Young Children, 18(3), 174-185.

Technical Assistance Project. (2000, July). Update on the use of assistive technology among infants and toddlers. TAP Bulletin, pp. 1-8.

Stayton, V., \& Bruder, M. E. (1999). Early intervention personnel preparation for the new millennium: Early childhood special education. Infants and Young Children, 12, 59-69.

Sullivan, M., \& Lewis, M. (2000). Assistive technology for the very young: Creating responsive environments. Infants and Young Children, 12(4), 34-52.

U.S. Department of Education. (2006). Twenty-sixth annual report to Congress on the implementation of the Individuals with Disabilities Education Act. Washington, DC: U.S. Government Printing Office.

Wilcox, M. J., Dugan, L., Campbell, P. H., \& Guimond, A. (2006). Recommended practices and parent perspectives regarding at use in early intervention. Journal of Special Education Technology, 21(4), 716.

Wilcox, M. J., Guimond, A., Campbell, P. H., \& WeintraubMoore, H. (2006). Tots and Tech: A national survey of early intervention providers. Topics in Early Childbood Special Education, 26(1), 33-50. 